\title{
A IMPORTÂNCIA DA CONSCIENTIZAÇÃO DA GERAÇÃO ATUAL E FUTURA NA RECUPERAÇÃO E PRESERVAÇÃO DO MEIO-AMBIENTE
}

\section{Simone Horvatin}

Graduada em Letras - com especialização em Administração de Negócios, Brasil Graduada em Bachelor of Business CC1 (Bacharel em Economia), Alemanha

凶simone@supplygogreen.com

\section{BREVE HISTÓRICO SOBRE O MEIO AMBIENTE, DO PASSAdo ATÉ OS NOSSOS DIAS}

A poluição ambiental tem relação direta com o crescimento populacional mundial, industrialização e consumo. $\mathrm{O}$ gráfico abaixo demonstra isso rapidamente (consultas baseadas em fontes rápidas da Internet/Google). No gráfico é possível visualizar a relação de população X meio-ambiente. No ano 900, eram 250 milhões de habitantes. Em 1800, 900 anos depois, a população global havia aumentado em 4 vezes (ou seja, 1 bilhão). Já em 1875 eram 1,5 bilhões de habitantes globais. 1975, apenas 100 anos, o crescimento da população aumentou quase 3 vezes (para 4 bilhões). Hoje, 2016, estima-se que somos 7,4 bilhões!

Figura 1. Gráfico comparativo sobre crescimento populacional e os efeitos sobre o meio ambiente (entre 1875 - 2000)

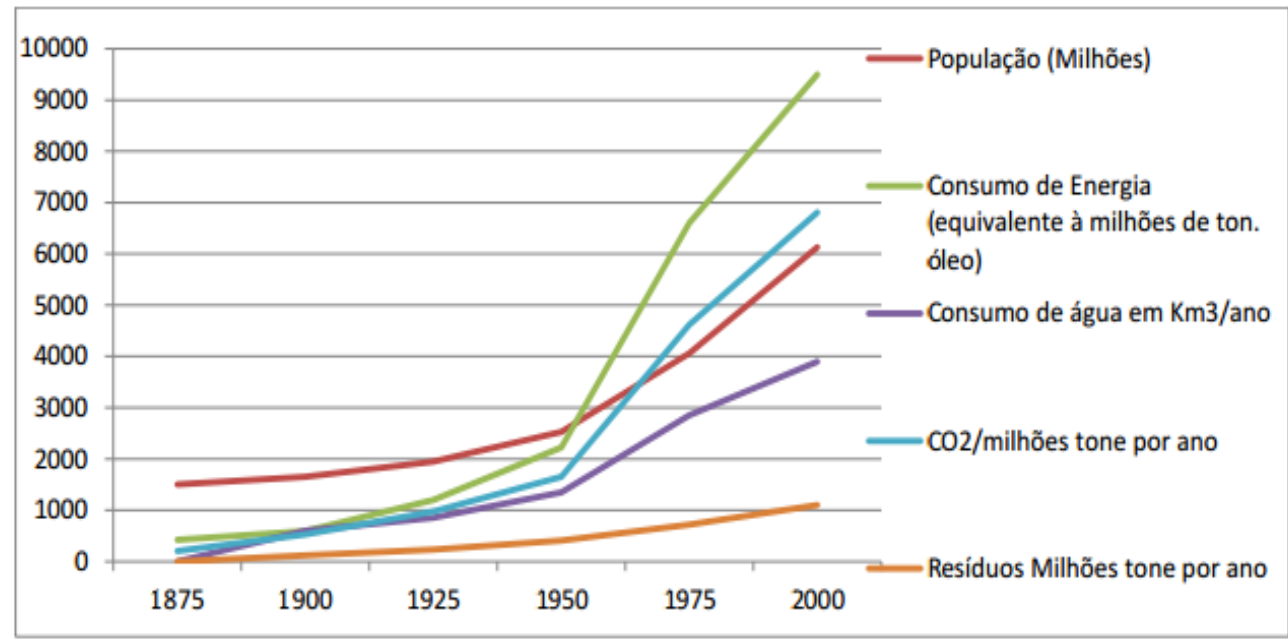

Na Europa, no ano de 1700, os habitantes exploravam os recursos essenciais (básicos desde que o homem é homem): água, madeira e animais. A forma para gerar energia era mecânica "Força = Trabalho/Tempo" (pois não havia eletricidade). Nesta época haviam: 14 milhões de cavalos e 24 milhões de bovinos (tração animal para trabalhos e transporte), - 
moinhos de vento, que eram usados para moagem de trigos e derivados (só na Holanda, haviam na época 8.000), - moinhos de água (rodas d'água), eram usados em toda Europa para moagem e trituração de diversas matérias, como: madeira, metais, rochas; e até para ventilação de minas. - Madeira: no século XVIII, a madeira na Europa era usada principalmente para construções de embarcações, casas, poços e apoios a túneis (contra deslizamentos). Também em fornos, para produzir vidros e porcelanas, derreter metais e produzir armamento e canhões (época de guerras), além do seu uso para aquecimento no inverno.

Percebe-se neste período o aumento do deflorestamento europeu, porém os efeitos de poluição não eram perceptíveis (pois a exploração dos combustíveis fósseis, principais poluidores, veio alguns anos depois).

A revolução industrial aconteceu entre 1760-1860: período de grande transição para a humanidade. Métodos manuais de produção foram substituídos por máquinas, surgiram novos produtos químicos e a introdução de novos processos para produção do ferro. Houve a melhoria da distribuição de água, o aumento crescente do uso de maquinários à vapor, o aumento de fábricas e a ascensão do sistema fabril.

Contando ainda com a invenção da lâmpada, a eletricidade e as primeiras redes de distribuição. A renda média e a população nesta época começaram a exibir um crescimento sem precedentes. Foi exatamente neste período que a população, de um século para outro, dobrou (em 1700 éramos 500 milhões de habitantes no mundo; em 1800, 1 bilhão).

Seguidamente, vieram os automóveis e sua fabricação em série. O avião, o aumento das companhias aéreas e suas frotas, facilitando o turismo de massa (prejudicial ao meioambiente, principalmente no quesito “consumo de água potável”, para povoados pequenos e regiões com escassez de água já comprovada).

Consequentemente, a exploração cada vez maior dos combustíveis fósseis: petróleo, gás e carvão. Sendo responsáveis pela emissão de $\mathrm{CO}_{2}$, em escalas, antes, inimagináveis. Fica claro que os problemas ambientais dos dias atuais tiveram seu marco inicial em meados de 1800 . 
Logo, no final do século $\mathrm{XX}$, houve o surgimento da informática e toda a sua evolução, possibilitando a comunicação ágil, com isso, expandiu-se o consumo, que antes era

, tornando-se global. Com o aumento do consumo, aumenta consequentemente a exploração dos recursos naturais.

Entre 1875 a 2000, observa-se que: o consumo de energia mundial aumentou em 16 vezes, o consumo de água potável aumentou em 10 vezes, a produção de lixo (resíduos sólidos) aumentou em 16 vezes e a emissão de $\mathrm{CO}_{2}$ aumentou 60 vezes!

Hoje temos uma hiperexploração dos recursos naturais de forma mega veloz! O aquecimento global e as mudanças climáticas são apenas algumas das consequências. Contaminamos e poluímos nossa atmosfera, nossos solos, nossos rios e oceanos. É como se dirigíssemos um carro de fórmula um $(400 \mathrm{Km} / \mathrm{h})$ e de repente, precisássemos “frear”!

Esta é a consciência que devemos ter sobre o meio-ambiente atual: temos que "frear" já! Através de leis rígidas, cobranças de impostos ambientais (que retornem para projetos ambientais) e multas severas e consequentes. Assim como, a participação ativa do governo, como criação de incentivos fiscais, de campanhas de educação ambiental, de apoio às empresas para que possam atingir um objetivo de "Zero Waste" na sua produção e uma otimização eficiente da logística reversa aos produtos fabricados, fazendo a cadeia funcionar, como já funciona na Europa.

\section{MEU OLHAR PROFISSIONAL}

O meio-ambiente representa o nosso presente e o futuro das próximas gerações. Sob minha perspectiva, há no Brasil muita passividade e falta de vontade política (a base) para resolver "com verdade" os problemas ambientais. Se o governo se dedicasse em resolver os problemas ambientais, assim como constrói hidroelétricas, acho que muito dos problemas já seriam coisa do passado. Podemos analisar o meio-ambiente por várias vertentes: por exemplo, o saneamento no Brasil, que ao meu ver é uma vergonha (e na minha opinião, uma das razões da proliferação do Aedes aegypti).

Não há mais tempo para discussões e teorias, para "sonhar com um mundo melhor". Chega de desculpas! Temos de agir, nos engajar como sociedade, reconhecer que já existem 
tecnologias e investir nelas: soluções que podem reverter processos poluentes e agressivos ao meio-ambiente, que podem melhorar a relação ser-humano e meio-ambiente para o futuro.

$\mathrm{Na}$ perspectiva econômica, o meio-ambiente é hoje um mercado tecnológico e científico em crescimento. Cada vez mais instituições e empresas, de países desenvolvidos, investem em pesquisas e desenvolvimento de produtos Green-tech. Países estes que já superaram parte do seu passado "sujo", possuindo um histórico de experiências práticas de recuperação ambiental, como por exemplo, a despoluição do rio Tâmisa, na Inglaterra (http://www.telegraph.co.uk/news/earth/wildlife/8059970/The-clean-up-of-the-River-

Thames.html).

Países que evoluíram no tratamento de água e saneamento, numa cadeia funcional para reciclagem de resíduos sólidos dos mais variados. Além de terem metas claras para substituir nos próximos anos, as energias fósseis e nucleares pelas energias renováveis. Isso só acontece, quando há interesse do governo e a participação ativa da sociedade. Não tenho nem a pretensão, nem a capacidade de debater temas ambientais com propriedade, pois existem profissionais excepcionais e altamente qualificados, além de pesquisadores com profundos conhecimentos de causa e trabalhos publicados.

Profissionalmente, considero-me uma "intérprete das necessidades ambientais", usufruindo do privilégio de viver há mais de 16 anos no país mais ecológico do mundo, a Alemanha. Aplico minhas habilidades profissionais e conhecimentos adquiridos em tecnologias (além da fluência em três idiomas), para buscar produtos, soluções e tecnologias que são eficientes e testadas na Europa, porém desconhecidas, ou não possuem representantes no Brasil.

"Quando escolhi a selva para aprender a ser, folha por folha, estendi as minhas lições e aprendi a ser raiz, barro profundo, terra calada, noite cristalina, e pouco a pouco mais, toda a selva" (O caçador de raízes, Pablo Neruda).

Um dos meus poemas preferidos, que exemplifica o simples: tudo leva tempo, mas o ponto de partida é o querer. O querer nos leva a ter que escolher, nos obrigando a sair da passividade, depois temos de estarmos dispostos a aprender (sair da zona de conforto). E a cada lição aprendida, passamos para a próxima... até o dia que que seremos capazes de ser "toda a selva". 
A autora- Trabalha com desenvolvimento de mercados, marketing e vendas internacionais, sobretudo para difusão de tecnologias ambientais. Idealizadora e fundadora das empresas: SUPPLYgoGREEN Spreading clean technologies for a clean world (http://www.supplygogreen.com) e AMBIENTAL MERCANTIL O portal mais ambiental do Brasil (http://ambientalmercantil.com).

\section{AGRADECIMENTOS}

Agradeço a Stefan Horvatin, cientista e desenvolvedor de softwares (softelecGmbH), pelas reflexões e conversas, que foram enriquecedoras para que eu pudesse refletir e escrever este artigo.

\section{REFERÊNCIAS CONSULTADAS}

AMBIENTAL mercantil. Disponível em: <http://ambientalmercantil.com/>. Acesso em: 12 jun. 2016.

GRAY, Richard. The clean up of the River Thames. The Telegraph. Londres, 13 out. 2016. Disponível em: $\langle$ http://www.telegraph.co.uk/news/earth/wildlife/8059970/The-clean-up-of-the-River-Thames.html〉. Acesso em: 12 jun. 2016.

HOORNWEG, Daniel; BHADA-TATA, Perinaz; KENNEDY, Chris. Environment: Waste production must peak this century. Nature, Londres, v. 502, n. 7473, p.615-617, 30 out. 2013. Disponível em: $\langle$ http://www.nature.com/news/environment-waste-production-must-peak-this-century-1.14032>. Acesso em: 16 fev. 2016.

PAEGER, Jürgen. Eine kleine Geschichte des menschlichen Energieverbrauchs. Disponível em: <http://www.oekosystem-erde.de/html/energiegeschichte.html >. Acesso em: 12 jun. 2016.

QUASCHNING, Volker. Erneubare Energie und Klimaschutz. 3. ed. Munique: Hanser, 2013. 384 p. Disponível em: 〈http://www.volker-quaschning.de/publis/klimaschutz/index.php〉. Acesso em: 12 jun. 2016.

SUPPLYGOGREEN. Disponível em: <http://www.supplygogreen.com/>. Acesso em: 12 jun. 2016.

WIKIPEDIA. Food and Agriculture Organization. Disponível em: 〈https://en.wikipedia.org/wiki/Food_and_Agriculture_Organization〉. Acesso em: 12 jun. 2016.

WIKIPEDIA. Forest History Society. Disponível em: 〈https://en.wikipedia.org/wiki/Forest_History_Society>. Acesso em: 12 jun. 2016.

WIKIPEDIA. Industrial Revolution. Disponível em:〈https://en.wikipedia.org/wiki/Industrial_Revolution〉. Acesso em: 12 jun. 2016.

WIKIPEDIA. Kohlenstoffdioxid in der Erdatmosphäre. Disponível em: 〈https://de.wikipedia.org/wiki/Kohlenstoffdioxid in der_Erdatmosphäre〉. Acesso em: 12 jun. 2016. 


\section{A IMPORTÂNCIA DA CONSCIENTIZAÇÃO DA GERAÇÃO ATUAL E FUTURA NA RECUPERAÇÃO E PRESERVAÇÃO DO MEIO-AMBIENTE}

WIKIPÉDIA. Petróleo. Disponível em: 〈https://pt.wikipedia.org/wiki/Petróleo〉. Acesso em: 12 jun. 2016.

WIKIPÉDIA. Water use. Disponível em: 〈https://en.wikipedia.org/wiki/Water_use>. Acesso em: 12 jun. 2016.

WIKIPEDIA. World Population. Disponível em: 〈https://en.wikipedia.org/wiki/World_population>. Acesso em: 12 jun. 2016. 